\title{
Educar ao sonho, transformando a realidade
}

Paulo Lima

Bacharel em Filosofia, Teologia e Comunicação Social, jornalista educomunicador, fellow da Ashoka Empreendedores Sociais e diretor executivo da ONG Viração Educomunicação. E-mail: paulo@viracao.org

Resumo: História de vida de um jornalista educomunicador e empreendedor social que se define "sonhalista", um sonhador e idealista. Fundador e diretor executivo da ONG Viração Educomunicação, Paulo Lima é cearense de Fortaleza e vive entre o Brasil e a Itália. Ama recordar suas origens de favelado, justamente para lembrar que a mudança social é possível, que investir em processos de participação ativa e emancipadora de crianças e adolescentes é fundamental para construir uma sociedade justa e fraterna. É paulofreiriano desde os 14 anos, quando conheceu e utilizou o Método de Alfabetização Popular de Paulo Freire em atividades com adultos da favela Lagamar, onde nasceu e viveu boa parte de sua infância e juventude.

Palavras-chave: educação; comunicação; adolescência; juventude; direito.
Abstract: Life story of an educommunication journalist and social entrepreneur who defines himself as "dreamlist", a dreamer and idealist. Founder and executive director of the NGO Viração Educomunicação, Paulo Lima is from Ceará, Fortaleza and lives between Brazil and Italy. He loves to remember his origins in the slum, just to remind us that social change is possible and that investing in processes of active and emancipatory participation of children and adolescents is key to build a fair and fraternal society. $\mathrm{He}$ is a follower of Paulo Freire's ideas since age 14, when he met and used the Popular Literacy Method of Paulo Freire in activities with adults in the Lagamar favela, where he was born and lived much of his childhood and youth.

Keywords: education, communication, adolescence, youth, rights.

Dizia o pintor Pablo Picasso que o mais difícil é o primeiro ponto. Um ponto, uma tela, uma obra de arte. No meu caso, um ponto, uma frase, um primeiro parágrafo para iniciar este meu depoimento, como se fosse um diário de bordo. Na verdade, quando se escreve um depoimento desse tipo, é como se houvesse um encontro consigo mesmo. O Paulo que dialoga com Paulo. O sonhalista que procura entender a si mesmo por meio da escrita, das lembranças, dos pensamentos escondidos e escancarados como uma janela de uma casa de verão à beira da praia.

Eu, "sonhalista", ou seja, sujeito "sonhador e idealista", como me autodefino. E que busca viver uma comunicação integral e emancipadora, que prevê educar ao sonho, à esperança. É essa uma forma que encontrei para traduzir o que Paulo Freire chamava de "inédito-viável" em sua Pedagogia do oprimido. 


\section{A IMPORTÂNCIA DO NOME}

Meu ponto de partida é exatamente o meu nome ou duplo nome: "Vicente de Paulo". Ter um nome duplo é algo um tanto inusitado, às vezes complicado. Você nunca sabe como gostaria de ser chamado: "Vicente" ou "Paulo"? No final das contas, prevalece aquele acarinhado em família. Trata-se de herança familiar. Sim, em casa eu era "Paulo" para todos. Mas na escola, eis que ouço uma primeira violência verbal, nominal. Me chamavam por "Vicente" e isso me parecia estranho. O "Vicente" no final da lista de presença me soava quase um nome estrangeiro. E passei a senti-lo grudado a mim como um chiclete na sola do sapato. Para os professores e também para os colegas de classe e escola, eu era "Vicente". Até a universidade, não tive escolha. "É Vicente e ponto", dizia minha primeira professora do Colégio Circulo Operário. Fim de papo. Vence a voz do mais forte em tempos de ditadura militar, e também em sala de aula. Não posso jamais esquecer que sou filho da ditadura militar, que teve início em 1964 e durou até 1985. Esse ambiente e clima militaresco, presente ainda na escola, muito me incomodava e certamente isso foi ficando na minha mente, esperando, um dia, florescer alguma resposta.

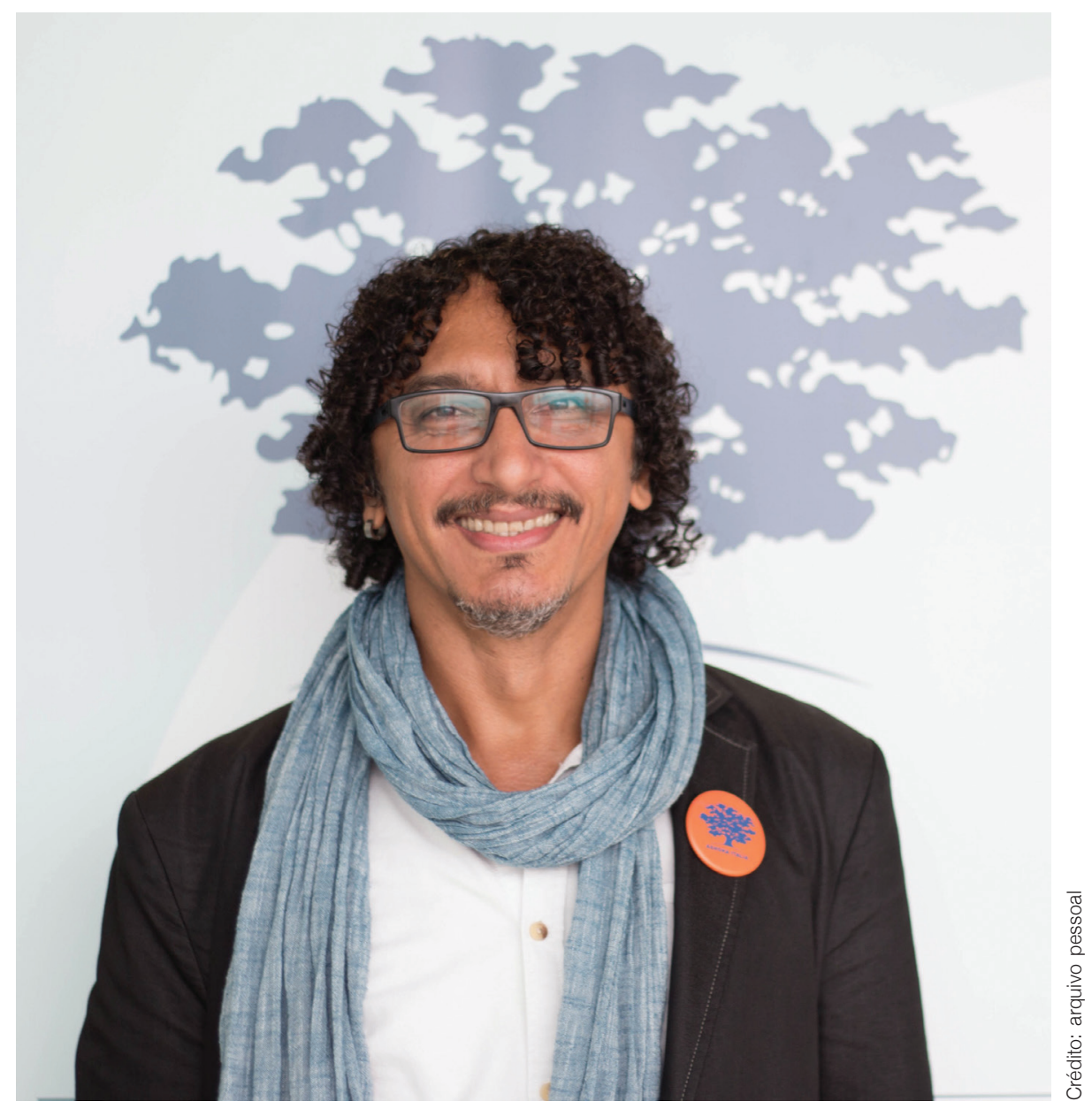


A vida, porém, reserva tantas surpresas. Para os amigos, eu não era nem "Paulo" nem "Vicente", mas "Paulão". Assim, me diferenciavam dos outros Paulos do grupo jovem paroquial ou do Lagamar, a favela onde nasci e vivi até os 15 anos. Foi a partir desse grupo de jovens ligado à Teologia da Libertação que conheci o Método Paulo Feire de Alfabetização Popular. E foi na favela que ajudei um grupo de adultos analfabetos a escrever a sua própria história e a mudar o mundo a partir dos ensinamentos do Mestre Paulo Freire. Eu tinha 14 anos na época. Essa minha experiência de voluntariado e de envolvimento na luta pelos direitos humanos me levou a radicalizar: entrei para o seminário. Eu tinha 17 anos. Queria ser missionário, me dedicar em tempo integral à causa dos empobrecidos, mas sempre por meio do exercício do direito humano à comunicação, concentrando todos os meus esforços em defesa de uma mídia livre. No entanto, depois de nove anos de estudos de Filosofia e Teologia e trabalhando com os movimentos sociais no Ceará, no Maranhão, em Minas Gerais e na Itália, resolvi viver minha missão como jornalista educomunicador e como empreendedor social. Lembro que conheci o professor Ismar de Oliveira Soares, do Núcleo de Comunicação e Educação da Escola de Comunicações e Artes da Universidade de São Paulo, por essas minhas vivências e andanças. Foi durante um curso que ele ministrou sobre "Leitura Crítica da Comunicação", por meio da então União Cristã Brasileira de Comunicação (UCBC), em 1985, em São Luís do Maranhão.

Dez anos depois, ingressei na Faculdade Cásper Líbero, em São Paulo. Ao mesmo tempo, atuei na revista Sem Fronteiras, dos Missionários Combonianos. Cheguei a ser diretor e promover campanhas de mobilização em defesa dos direitos de crianças e adolescentes.

Parece esquisito, mas na época não bastavam os nomes e apelidos que me davam: lá pelos 30, decidi ter um codinome - Moisés Araújo. Nome e sobrenome novos em homenagem à minha mãe, Maria. Ela sempre desejou que um filho levasse seu sobrenome, Araújo, e o nome Moisés. Quando nasceu meu irmão menor, Moésio, prevaleceu a vontade de meu pai. Nada de Moisés, mas Moésio, uma variante do nome Moisés. Moisés Araújo, pois. Como jornalista, era assim que eu assinava os artigos que escrevia na coluna da "Revista Já” do jornal Diário de São Paulo, no final dos anos 1990. Todos os domingos, eu contava a história de vida de alguém que estava mudando, para melhor, a cidade de São Paulo. Era gente simples: da voluntária anônima de uma casa de repouso ao artista tetraplégico que pintava com a boca.

Voltando ao "Vicente de Paulo". Pesquisei a origem dos nomes - e descobrir seu significado foi uma agradável surpresa. "Um pequeno vencedor", eis o significado de meu nome. Vicente deriva do latim "vincentius" e quer dizer exatamente "aquele que está vencendo", "vencedor". Também Paulo vem do latim e tem origem antiguíssima. Deriva do adjetivo "paulus", ou seja, "pouco grande". Na realidade, já beirando os 50 , me sinto realmente como um pequeno vencedor. 


\section{LUGAR SOCIAL DE ONDE VENHO}

Às vezes, alguém me pergunta a razão do meu compromisso social ou de certas escolhas de vida baseadas, essencialmente, na simplicidade e na solidariedade. Pode parecer estranho, mas nesses momentos não me vem à mente nenhuma resposta; para mim é natural viver assim. Depois, começo a refletir e, então, me surgem lembranças da minha infância. Aparecem imagens do meu primeiro lugar social, no qual nasci e vivi até a adolescência: a favela do Lagamar, em Fortaleza.

Com certeza estão ali as origens das minhas opções e projeto de vida de hoje, do passado e, espero, do futuro. Se hoje sou um jornalista educomunicador e empreendedor social - que se ocupa dos problemas e das soluções, dos protestos e das propostas, dos desafios e das inovações sociais no campo da educação e da comunicação —, é, em grande parte, devido ao meu primeiro contexto social em que nasci e vivi, às minhas origens, às minhas raízes. Origens também indígenas por parte de mãe e africana por parte de pai.

As lembranças da infância são muitas, e ligadas, infelizmente, à negação de direitos. Eu era muito pequeno na primeira vez em que assisti a um episódio de violência policial, por exemplo. Eu estava participando, com meu pai, da ocupação (não invasão) de um terreno público abandonado, ao lado da nossa favela. Aquele bom homem tentava construir uma ou duas barracas de madeira para seus irmãos que moravam em Tianguá, uma pequena cidade no interior do Ceará. A ideia era trazer para Fortaleza dois de meus tios e suas respectivas famílias, porque a capital prometia melhores condições de vida. E, apesar de ser o mais novo da família, meu pai sempre teve o papel de "irmão maior", uma espécie de guardião.

Corriam os tempos da ditadura militar e as ocupações de sem-teto não eram permitidas. Depois de poucos dias, as pequenas casas de madeira foram arrancadas do chão pelos funcionários da prefeitura, e as pessoas foram afastadas pelos policiais, armados com cavalos, cassetetes e gás lacrimogênio. A violência por parte do Estado está entre as piores que existem, porque você não sabe a quem recorrer para pedir ajuda. Você se sente impotente.

A cena era de guerra. Gritos e lágrimas, muita raiva e medo. Crianças e mulheres que corriam de um lado para o outro, para se defenderem junto aos seus pais ou maridos. O mau cheiro do canal sem saneamento - que fazia do terreno um grande pântano - se misturava àquele do gás lacrimogênio lançado pela polícia e àquele das fezes dos seus cavalos. Em poucos segundos, olhos, nariz e garganta começaram a queimar insuportavelmente. Uma dor fortíssima me rasgava o corpo e a alma. Eu lacrimejava como um rio, enquanto sentia os pulmões se contraindo no esforço de expelir o gás. Chorava como um recém-nascido em sua primeira e difícil respiração.

É difícil apagar essas imagens da mente quando se experimenta algo do gênero com apenas 5, 6 anos de idade. Se tivesse que resumir em uma só palavra o que senti, diria: m-e-d-o. O mesmo medo que experimentava quando sentia 
o barulho ensurdecedor dos aviões supersônicos que sobrevoavam nossa favela, situada ao lado de uma base militar da Aeronáutica. O fato de serem exercícios corriqueiros não era o suficiente para me tranquilizar. As casas tremiam. As pessoas saíam para a rua pensando que fosse um terremoto. Um barulho infernal, de guerra, que me fazia disparar o coração e me sentir perdido. Um terror de fim do mundo. O mesmo medo que sentia vendo os palhaços de pernas de pau, que anunciavam a chegada do circo em um campinho vizinho à minha casa. Lembro-me de me esconder debaixo da saia de minha mãe ou dentro de um armário, com medo que aqueles homens estranhamente vestidos e mascarados viessem me pegar e me levar embora. $\mathrm{O}$ mesmo medo das balas perdidas disparadas entre os criminosos que queriam dominar o tráfico na favela. Um dia, encontrei uma no quintal de casa. O mesmo medo da morte, ou melhor, de depois da morte, quando, à noite, me estendia na calçada em frente à minha casa e ficava olhando as estrelas, me perguntando: o que haverá depois da morte? Pensava no nada. Não vou encontrar mais ninguém. Tudo vai acabar. Nenhuma emoção. Sem pais ou irmãos. Sem amores. Nada. E começava a chorar, perdido no abismo dessas elucubrações. Sentia um vazio dentro de mim. E pensar que esses pensamentos obscuros me acompanharam até a juventude.

Encontrei-me na mesma situação de ocupação de terras tantas outras vezes, como jovem e adulto. Marchei com os sem-terra e com os sem-teto nas periferias das cidades onde vivi (São Luís do Fortaleza, São Luís, Belo Horizonte, São Paulo) e participei de manifestações no Brasil e na Europa. Por fim, o medo se tornou um companheiro de viagem. Agora, mais consciente dos riscos e das portas de saída, procuro domá-lo.

\section{VIRAÇÃO: QUANDO EDUCAÇÃO E COMUNICAÇÃO SE ABRAÇAM E MUDAM O MUNDO}

Voltando a falar da origem das palavras e nomes, muitas pessoas me perguntam o que significa Viração, a organização que criei em março de 2003. A palavra "viração" tem diversos significados.

Em primeiro lugar, significa "se arranjar", "sobreviver decididamente". Uma palavra que faz parte das gírias das crianças em situação de rua de São Paulo. Há anos, lendo um livro de antropologia de Maria Filomena Gregori intitulado justamente Viração, fiquei positivamente impressionado e intrigado com a força intrínseca desse nome. Arranjar-se, emergir, abrir caminho, manter a cabeça erguida... bonito, gostei do conceito. Gostei também da sonoridade: muito brasileira, característica, nasal.

Tentei visualizá-lo mentalmente. Fechei os olhos e apareceu-me um exército de pequenos guerreiros da paz, garotos tenazes que, com dignidade e orgulho, resistem às frustrações da vida. Combatentes dispostos a nunca desistir, a não baixar a cabeça. Almas frágeis, mas também fortes, como troncos de bambu 
que se dobram ao vento, mas não se quebram. Pequenos guerreiros, vencedores... como o meu nome! Estranha coincidência, não? O texto da Gregori era sobre um estudo antropológico de grupos de crianças de rua que viviam em São Paulo em situação de risco. Na linguagem comum dos jovens, o termo "virar" quer dizer "dar certo", é uma palavra cool. Aprofundando mais tarde o termo "viração", encontrei outros significados. Um deles é "brisa do mar". Viração é aquele vento fresco que sopra do leste no litoral do meu estado do Ceará, banhado pelo Atlântico.

Durante o Fórum Social Mundial de Porto Alegre, em 2005, descobri que, no sul do Brasil, viração quer dizer também prostituição. Disso eu gostei menos... me pareceu pobre. Triste. Pensei nas crianças de rua ou da minha favela, o Lagamar, em Fortaleza, que por poucos trocados vendem seus frágeis e pequenos corpos. Cordeiros imolados no altar do sacrifício. Vítimas inocentes e inconscientes de um mundo doente e de um sistema econômico que quer mercantilizar tudo, inclusive as crianças. Vítimas da exploração, como foi Iqbal Masih - ele, porém, de outro tipo de exploração, aquela do trabalho infantil.

Confesso que guardo comigo a sete chaves uma espécie de "personário", ou seja, uma lista de pessoas que me encorajam a levar adiante os meus ideais. Entre elas está o argentino Che Guevara, o indiano Mahatma Gandhi, o americano Martin Luther King, o brasileiro Chico Mendes... e Iqbal Masih. A lista é longa. Gente de todos os cantos e culturas.

Quando sou convidado a dar palestras ou realizar outros tipos de atividades para crianças e adolescentes, jovens e adultos, sempre falo mais do exemplo deixado por Iqbal Masih do que de qualquer outra pessoa que me inspira. Emociono-me e minha voz fica embargada, como se eu tivesse um nó na garganta. Isso porque Iqbal era um menino ativista que se tornou símbolo da luta contra o trabalho infantil em todo o mundo, não só em seu país, o Paquistão.

De acordo com a Wikipedia, Iqbal nasceu em 1983 em uma família muito pobre. Aos 4 anos, já trabalhava em uma fábrica de tijolos. Para pagar uma dívida familiar equivalente a 12 dólares, Iqbal foi cedido a um fabricante de tapetes. Foi obrigado a trabalhar de 10 a 12 horas por dia na linha de produção, subnutrido, o que trouxe prejuízos ao seu crescimento. Em 1992, conseguiu sair escondido da fábrica e participou, junto a outras crianças, de uma manifestação do Bonded Labour Liberation Front (BLLF), organização fundada por Ullah Khan que obteve, no mesmo ano, a promulgação do Bonded Labor System Abolition Act. Ao voltar à fábrica, ele se recusou a continuar trabalhando. Ameaçada por desconhecidos, a família foi obrigada a abandonar o vilarejo, e Iqbal, abrigado em um alojamento da BLLF, recomeçou a estudar. E não só isso. Passou a participar de eventos nacionais e internacionais, denunciando abusos e contando sua experiência. Dizia: "Nenhuma criança deveria jamais empunhar uma ferramenta de trabalho. As únicas ferramentas de trabalho que uma criança deveria ter nas mãos são canetas e lápis”.

Infelizmente, quando tinha apenas 12 anos, em 16 de abril de 1995, Iqbal foi morto pela Máfia dos Tapetes enquanto andava de bicicleta em seu vilarejo. 
Quando penso nisso, sinto uma dor forte no fundo do coração... lágrimas secas lavam meu rosto e meus pensamentos. Incapaz até mesmo de chorar, aperto os punhos, renovando meu compromisso para continuar minha missão pessoal para fazer valer os direitos humanos por meio da Educomunicação.

Voltando à Viração, anos depois, descobri ainda outro significado para o termo. Com entusiasmo, verifiquei que esse é também o nome de uma corrente no interno do Partido Comunista Brasileiro. Às vezes, recebo cartas ou e-mails de militantes comunistas que desejam me cumprimentar pela criação da revista Viração, nosso primeiro grande projeto social.

Sinceramente, 13 anos atrás, quando sugeri esse nome à associação que eu havia criado, pensei em um jogo de palavras: vira-ação, ou seja, "o que se torna ação", "colocar o time em campo". Algo não muito definido, como o vento; que desafia, que surpreende. Enfim, como dizia nosso educador Paulo Freire, "um processo indefinido, incompleto", um movimento constante de renovação e inovação social.

Parece que, 13 anos depois, continuamos a nos surpreender todos os dias.

Escolher o nome de uma associação é como escolher o nome de um filho. É preciso ter paciência, muita pesquisa e diálogo. Mas, sobretudo, é preciso haver feeling entre as pessoas e respeito pelas ideias. Antes de tudo, junto à equipe de amigos e colaboradores dispostos a participar da aventura de criar uma associação sem fins lucrativos que trabalhasse com Educomunicação e a defesa dos direitos de adolescentes e jovens, começamos a procurar alguma coisa simples, imediata e espontânea. Um nome sob medida que, além de transmitir a filosofia da iniciativa, soubesse também representá-la e descrevê-la da melhor forma.

Procuramos fazer um brainstorm, levando em conta que o nome deveria ser breve, simples de ser lembrado, original e que fizesse referência à inovação social e ao cotidiano dos movimentos que trabalham na defesa dos direitos das crianças, adolescentes e jovens. Viração foi muito bem acolhido.

Viração nasceu como uma iniciativa pessoal e, aos poucos e logo logo, foi se tornando obra coletiva. Primeiro, surgiu como revista, com base nos pressupostos defendidos pelo Núcleo de Educação e Comunicação da Universidade de São Paulo (NCE). Além de pesquisar sobre a Educomunicação, o NCE desenvolvia, naquele momento, um projeto pioneiro para levar a comunicação participativa, por meio da linguagem radiofônica, a todas as escolas da rede municipal de educação de São Paulo, o Educom.rádio. À época, eu era diretor da revista Sem Fronteiras e tinha recebido o Prêmio Jornalista Amigo da Criança, concedido pela Andi Comunicação e Direitos, Unicef e Fundação Abrinq.

Contei com o apoio jurídico dos Missionários Combonianos e da Associação de Apoio às Meninas e Meninos da Região Sé. Depois, o projeto foi crescendo, várias organizações foram pedindo para a gente ir irradiando nosso jeito de fazer educomunicação em outras paradas: consórcio social da juventude, escolas, ONGs, Igrejas, secretarias de governos e ministérios. Os Conselhos Jovens da Revista Viração, chamados "Virajovens", foram se espalhando como 
"maria-sem-vergonha" num jardim e ganhando Brasil afora. Nesse processo, sempre acreditamos na força do colaborativo e do cooperativo. Por isso, fomos tecendo parcerias com outras organizações que também assumiam a causa de uma comunicação livre.

Podemos melhor entender os primeiros momentos da Viração com uma analogia do ambiente vegetal. É costume dizer que as árvores nascem das sementes. Mas como poderia uma sementinha gerar uma árvore enorme, uma mangueira, por exemplo? Pois bem, as sementes já contêm os recursos necessários ao crescimento de uma árvore. Esses recursos vêm do ambiente onde ela nasce. $\mathrm{O}$ ambiente em que foi gerada Viração era muito fecundo. Estávamos embalados pela grande novidade que representou o Fórum Social Mundial. Estávamos embalados pelo primeiro governo Lula. Era março de 2003. O ambiente em que nasceu a Viração era propício.

Mas não foi nada fácil chegar até aqui. Ouvi muitos nãos. Foram muitos os tempos de vacas magras. Lembro que apresentava a Viração para potenciais financiadores e inscrevia projetos de sustentabilidade em diversos editais. A cada negativa, eu comprava um vaso de plantas ou flores para amenizar a frustração e transmutar o sentimento deixado pela porta fechada. Mas as portas e janelas, aos poucos, foram se abrindo. A gente foi sendo conhecido e reconhecido, no Brasil e no exterior; no ambiente acadêmico e no movimento social que defende a democratização da cultura e da comunicação.

Gostaria de ressaltar que, eu mesmo e minha organização, começamos a impactar mais com nossas ações e projetos sobretudo quando, em 2006, fui selecionado pela Ashoka Empreendedores Sociais para ser fellow. Praticamente 10 anos depois, sinto um orgulho imenso em participar dessa rede mundial que reúne cerca de 3 mil pessoas de todo o mundo e que está promovendo mudanças em vários campos e setores.

Hoje, vivo entre o Brasil e a Itália, atuando em ambos os países por meio da Viração, mas também trabalhando com outros países europeus e africanos. Estou compartilhando experiência de vida e profissional no campo da Educomunicação com adolescentes e jovens, coletivos juvenis e organizações sociais.

Essa pequena história de vida, pessoal e coletiva, faz jus à própria palavra "viração", que vale lembrar novamente, significa, entre tantos significados, justamente: "virar ação", "sobreviver de forma aguerrida", "dar certo".

E vale ressaltar que, depois de 13 anos, a organização continua sendo um processo indefinido, inacabado, em constante movimento de renovação e inovação. E eu também vou pegando carona, como pessoa inacabada, em contínuo processo de formação e me surpreendendo dia a dia com a Vida. 